\title{
Class Comparison
}

National Cancer Institute

\section{Source}

National Cancer Institute. Class Comparison. NCI Thesaurus. Code C61038.

A type of analysis that determine the significance and/or magnitude of the difference between groups. 